NASA Technical Memorandum 88920

AIAA-87-0526

\title{
Measured Noise of a Scale Model High Speed Propeller at Simulated Takeoff/Approach Conditions
}

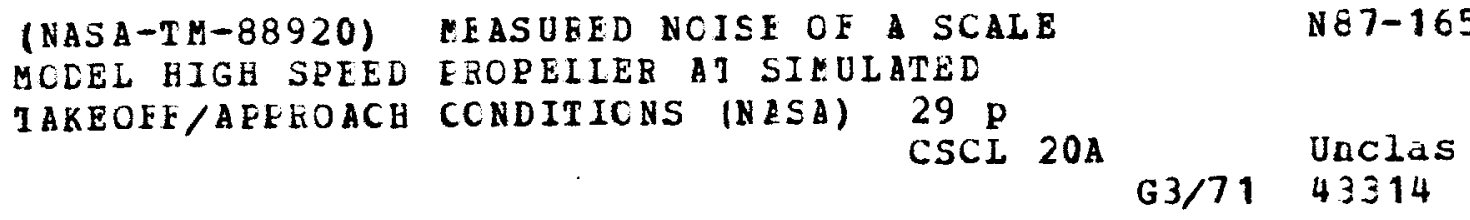

Richard P. Woodward Lewis Research Center Cleveland, Ohio

Prepared for the 25th Aerospace Sciences Meeting sponsored by the American Institute of Aeronautics and Astronautics Reno, Nevada, January 12-15, 1987 
MEASURED NOISE OF A SCALE MODEL HIGH SPEED PROPELLER

AT SIMULATED TAKEOFF/APPROACH CONDITIONS

\author{
Richard $P$. Woodward \\ National Aeronautics and Space Administration \\ Lewis Research Center \\ Cleveland, Ohio 44135
}

\title{
SUMMARY
}

A model high-speed advanced propeller, SR-7A, was tested in the NASA Lewis 9- by 15-ft Anecholc Wind Tunnel at simulated takeoff/approach conditions of 0.2 Mach number. These tests were in support of the full-scale "Propfan Test Assessment" (PTA) flight program. Acoustic measurements were taken with fixed microphone arrays and with an axially translating microphone probe. Limited aerodynamic measurements were also taken to establish the propeller operating conditions. Tests were conducted with the propeller alone and with three downstream wing configurations. The propeller was run over a range of blade setting angles from $32.0^{\circ}$ to $43.6^{\circ}$, tip speeds from 183 to $290 \mathrm{~m} / \mathrm{sec}$ (600 to $950 \mathrm{ft} / \mathrm{sec}$ ), and angles of attack from $-10^{\circ}$ to $+15^{\circ}$. The propeller alone BPF tone noise was found to increase $10 \mathrm{~dB}$ in the flyover plane at $15^{\circ}$ propeller axis angle of attack. The installation of the straight wing at minimum spacing of 0.54 wing chord increased the tone noise $5 \mathrm{~dB}$ under the wing at $10^{\circ}$ propeller axis angle of attack, while a similarly spaced inboard-up swept wing only increased the tone noise $2 \mathrm{~dB}$.

\section{INTRODUCTION}

Modern high performance turboprop aircraft offer the promise of considerable fuel savings while still allowing for a cruise speed similar to that of current turbofan aircraft (refs. 1 and 2 ). However, there is considerable concern about the potential noise generated by such aircraft, which includes both in-flight cabin noise and community noise during takeoff and landing. This noise may be affected by propeller inflow conditions including installation effects such as propeller axis angle of attack and interactions between a wing flow field and the propeller.

This paper presents acoustic results for the SR-7A scale model of the large-scale advanced propfan (LAP) propeller. The SR-7A propeller was tested in the NASA Lewis 9- by 15-ft Anechoic Wind Tunnel. All tests were performed at 0.2 tunnel Mach, which is representative of the aircraft takeoff/approach speed. Limited aerodynamic measurements were made to determine the propeller operating conditions. The SR-7A propeller was also tested at cruise conditions (Mach 0.5 to 0.9 ) in the NASA Lewis B- by 6-ft Wind Tunnel where the data taken were primarily aerodynamic with limited acoustic measurements (ref. 3). These tests were in support of the future "Propfan Test Assessment" (PTA) filght program which will involve tests of the full-scale LAP propeller on a modified Gulfstream II aircraft (ref. 4).

Acoustic results are presented in this paper for the SR-7A propeller alone, and for the SR-7A propeller in a tractor installation with both straight and $30^{\circ}$ swept wings. Two sets of swept wings were tested to simulate both an 
inboard up and inboard down installation with respect to propeller rotation. The propeller was tested over a range of tip speeds (from 183 to $290 \mathrm{~m} / \mathrm{sec}$ ) (600 to $950 \mathrm{ft} / \mathrm{sec}$ ), blade setting angles from $32.0^{\circ}$ to $43.6^{\circ}$, and angles of attack from $-10^{\circ}$ to $+15^{\circ}$. Acoustic signals were obtained from both fixed microphone arrays on the tunnel floor, near wall, and ceiling, and from a translating microphone probe which provided surveys of the acoustic field from about $25^{\circ}$ to $140^{\circ}$ relative to the propeller inflow.

\section{APPARATUS AND PROCEDURE}

The NASA Lewis 9- by 15-ft Anechoic Wind Tunnel is located in the lowspeed return loop of the supersonic 8 - by 6 - $\mathrm{ft}$ Wind Tunnel. The maximum airflow velocity is slightly over 0.2 Mach, which provides a takeoff/approach test environment. The tunnel acoustic treatment was modified prior to the SR-7A tests to provide anechoic conditions down to a frequency of $500 \mathrm{~Hz}$., which is lower than the range of the fundamental tone produced by the SR-7A propeller.

Acoustic instrumentation in the 9 - by $15-\mathrm{ft}$ tunnel consisted of fixed arrays of $0.64 \mathrm{~cm}$. $(0.25 \mathrm{in.})$ condenser microphones on the tunnel floor, near wall, and celling and two similar microphones on a remotely-controlled translating microphone probe. The fixed microphone arrays were mounted on wooden support beams positioned $61 \mathrm{~cm}(24 \mathrm{in}$.$) from the wall and were staggered at$ about $10^{\circ}$ to the tunnel flow to prevent microphone wakes from impinging on downstream microphones. The translating microphone probe traversed $6.50 \mathrm{~m}$ $(21.33 \mathrm{ft})$ which covered most of the $8.2 \mathrm{~m}(27 \mathrm{ft})$ length of the treated test section. The translating probe measured noise which would correspond to an observer located below an aircraft during a level flyover. The fixed near wall microphone array measured noise "above the aircraft" while the fixed floor and celling microphone arrays measured horizontal sideline nolse. The acoustic signals were recorded on magnetic tape for later constant-bandwidth analysis (25 $\mathrm{Hz}$ bandwidth for the fixed microphones, $20 \mathrm{~Hz}$ bandwidth for the transversing microphone). Limited aerodynamic instrumentation was also provided to establish the propeller operating conditions.

Figure 1 is a photograph of the SR-7A propeller installed in the 9- by 15-ft tunnel. The acoustic instrumentation is clearly seen in this picture. The SR-7A propeller was powered by an air turbine drive system. The support structure for the propeller extended between the tunnel floor and ceiling as shown in figure 1 . This structure was mounted on a turntable which provided for remote positioning of the propeller axis to angle of attack in the horizontal plane. Figure 2 is a plan view of the propelier installation in the 9- by 15-ft tunnel. The propeller rotated in a clockwise direction looking downstream, and a positive angle of attack was denoted as being toward the near wall fixed microphone array.

The SR-7A propeller is an aeroelastic scale model of the SR-7L propeller which is to fly on a modified Gulfstream II aircraft. Cruise design parameters for this propeller are presented in table $I$. The data presented in this paper are for the takeoff/approach condition at 0.2 Mach. "Design" values used at this airspeed were a blade angle of $37.8^{\circ}$ and a blade tip speed of $244 \mathrm{~m} / \mathrm{sec}$ $(800 \mathrm{ft} / \mathrm{sec})$. This gives a nominal takeoff advance ratio of 0.89 and power coefficient of 0.85 . The SR-7A propeller is aerodynamically similar to the model SR-3 propeller. Reference 5 gives detalled aerodynamic results for SR-3 
at flight speeds of 0.10 to 0.34 Mach in the NASA Lewis 10- by 10-ft Wind Tunnel. Reference 6 explores the design advantages of blade sweep in the SR-7A propeller.

Figure 1 shows a straight wing installed downstream of the propeller. Three wing sets were installed downstream of the SR-7A propeller to investigate the acoustic effects of propeller-wing interaction. A straight wing and two $30^{\circ}$ swept wings using the supercritical airfoll section of reference 7 were made for these tests. The two swept wings simulated inboard-up and inboarddown installations. The straight wing chord was $0.61 \mathrm{~m}(2.0 \mathrm{ft})$, and the effective chord of the swept wings was $0.70 \mathrm{~m}(2.3 \mathrm{ft})$. The propeller pitch change axts to wing leading edge spacings for the straight wing were 0.54 , 0.79 , and 1.30 wing chords; while the corresponding spacing (at the propeller tip to wing leading edge parallel to the propeller shaft axis) for the swept wings was 0.43 and 0.64 axial wing chords. In addition, the straight wing angle of attack could be changed relative to the propelier axis to explore the effect of propeller "droop angle". Oroop angle is defined in this paper as the angle of the propeller axis relative to wing chord measured negative downward. The $30^{\circ}$ swept wings did not have this independent wing angle of attack feature.

Table II presents the matrix of test conditions used in this investigation.

\section{RESULTS AND DISCUSSION}

All tests were performed at 0.20 Mach number. Limited aerodynamic results are presented to establish the propeller operating conditions. Acoustic results show how the propeller noise is affected by angle of attack, blade angle, tip speed, and wing installation.

Aerodynamic performance. - Figure 3 is a propeller operating map of the power coefficient, $C p$, as a function of the advance ratio, $J$. The advance ratio at takeoff conditions of $37.8^{\circ}$ blade angle (B) and $244 \mathrm{~m} / \mathrm{sec}(800 \mathrm{ft} / \mathrm{sec}$ ) tip speed is 0.89 and the power coeffictent is 0.85 . The operating map of figure 3 is for $0^{\circ}$ angle of attack.

Figure 4 shows how the power coefficient increases with increasing propeller angle of attack, indicating the increased drive air requirements to the air turbine as propeller angle of attack increased and mean loading was increased.

Propeller-alone acoustic performance. - The SR-7A propeller was tested over a range of 5 blade setting angles and at tip speeds from 75 to 119 percent design.

Spectral content. - Figure 5 shows a typical constant bandwidth spectrum for the SR-7A propeller. This spectrum is for the $90^{\circ}$ (propeller plane) microphone on the floor array. A corresponding windmill spectrum is also shown to give an indication of the tunnel background notse. Note that no propeller tones are visible above the background at windmi11. The tonal content of the SR-7A spectra is typically limited to the first three tone orders, with higher tone orders efther not present or masked by the substantial broadband noise content. Reference 8 likewise noted the importance of broadband noise at lower Mach numbers for single rotation propellers. 
The broadband noise content in the total spectra is further lllustrated in figure 6 which shows the SPL spectra for several propeller tip speeds for the $90^{\circ}$ floor microphone. Again, the windmill spectrum is superimposed on each of these spectra to indicate background noise levels. The broadband noise is clearly shown to become a significant part of the spectra at higher speeds.

Axial tone directivity. - The translating microphone probe provided surveys of the acoustic field from about $25^{\circ}$ to $140^{\circ}$ relative to the propeller inflow centerline. All of the translating probe results presented in this paper are for the inner microphone, which was located $1.68 \mathrm{~m}(5.5 \mathrm{ft})$ from the propeller axis at $0^{\circ}$ propeller axis angle of attack. As mentioned, the microphone probe results simulate an observer directly beneath a propeller flyover. In the wind tunnel the propeller axis rotated away from the probe in the horizontal plane at positive angle of attack.

Figure 7 shows the SPL tone directivity at $0^{\circ}$ angle of attack for the first two tone orders. The propeller was operated at design takeoff blade angle and tip speed. The lobular nature of the fundamental tone (BPF) is immediately evident. It is possible that the secondary lobes may be caused by reflective interference from the model support structure or microphone arrays. Inverse square law calibration tests of the empty tunnel showed that the wall treatment was effectively anechoic down to $500 \mathrm{~Hz}$. However, the main interest in this study is the maximum tone level, which always occurs near the $90^{\circ}$ location. Background noise level (windmill results from fig. 5) are shown on fig. 7 for the fundamental tone $(1000 \mathrm{~Hz})$ and the first overtone $(2000 \mathrm{~Hz})$. As expected from the spectra of figures 5 and 6 , the first overtone $(2 \times B P F)$ is considerably lower than the fundamental tone.

The actual traverse angle as a function of probe axial location changes with propeller angle of attack. Likewise, the acoustic levels must be corrected for distance effects at nonzero angles of attack. Table III shows the acoustic corrections that were used with model angle of attack. Thus, the traverse results (represented by fig. 7) were reduced to tone level at $5^{\circ}$ increments of traverse angle and normalized to $0^{\circ}$ propeller angle of attack.

Figure 8 shows the axial BPF tone directivity below an "aircraft" as a function of propeller angle of attack. The maximum tone level shows a considerable increase with positive angle of attack (away from the translating microphone), with $15^{\circ}$ angle of attack showing a $10 \mathrm{~dB}$ increase over the $0^{\circ}$ angle of attack results. Moving the model to negative angles of attack reduces the tone noise level observed by the microphone probe.

This asymmetry of the noise field is further explored in figure 9 which shows the circumferential distribution of the fundamental tone level at the propeller plane. Note the symmetry in tone level at $0^{\circ}$ propeller axis angle of attack. The BPF tone level at the near wall microphone (above the propeller in a flyover) is seen to behave in an opposite manner to that at the translating microphone probe. That is, tone increases at the translating microphone are accompanted by decreases at the $180^{\circ}$ opposing location on the near wall. The results for the floor and celling microphones which were located in the propeller plane at $0^{\circ}$ propeller angle of attack support these trends. However, the azimuthal increases in the directivity pattern at angle of attack are skewed toward the floor side. 
Figure 10 gives a qualitative explanation of this observed asymmetric circumferential noise fleld. For steady conditions propeller noise primarily radiates normal to the approaching blade. With positive angles of attack the propeller blade which is approaching the translating microphone probe (fig. 10(a)) is subjected to an increased effective blade angle as discussed in reference 9. Likewise, at negative angles of attack the blade approaching the translating microphone probe is at a reduced angle of attack. Changes in blade angle of attack result in corresponding changes in the blade loading and thus noise generation. At $0^{\circ}$ angle of attack the propeller blades see no angular change in blade loading and would be expected to generate a constant tone level with respect to circumferential position, as was observed for the $0^{\circ}$ angle of attack results of figure 9. With angle of attack the circumferential location of maximum notse might be expected to be $90^{\circ}$ ahead of the location of maximum blade loading for instantaneous (quasi-steady) blade response. However, the floor and celling microphone results of figure 9 show that the location of maximum noise is more than $90^{\circ}$ ahead of the maximum blade loading position ("c" in fig. $10(a)$ ). This suggests that the blade gust response to unsteady inflow conditions may shift the phase of the propeller blade pressures and consequently the peak in the circumferential directivity, as shown schematically in figure $10(b)$.

This asymmetrical circumferential noise distribution was observed for a single-rotation model propeller (refs. 10 and 11) which was tested in another wind tunnel at low axial velocity. Wind tunnel acoustic results for a counterrotating model propeller (ref. 12) operated at cruise conditions likewise showed a circumferential noise level distortion with propeller angle of attack. The circumferential location of maximum tone noise in reference 12 suggested that the blade response somewhat led, rather than lagged the actual location of maximum blade loading. The SR-3 propeller (aerodynamically similar to SR-7) was tested at cruise conditions with blade mounted pressure sensors (ref. 13). These SR-3 results at propeller angle of attack showed that the blade response usually lagged the circumferential region of maximum blade angle of attack.

Tip speed and blade angle effects. - The increase in tone SPL with tip speed for the first three tone orders is shown in figure 11 . Reference 3 showed that at constant advance ratio, J, the maximum BPF tone noise increased linearly with helical tip Mach number up to a tip Mach number of 1.1 where the slope abruptly turned downward. However, in figure 11 where $\mathrm{J}$ was allowed to vary, the tip Mach number is below 1.0.

Figure 12 shows the maximum tone SPL as a function of blade setting angle for $0^{\circ}$ and $15^{\circ}$ angle of attack. The tone level essentially increases directly with increasing blade setting angle (blade loading), but the slope is somewhat greater for the $15^{\circ}$ angle of attack results.

Aero-acoustic maps. - Figure 13 shows peak fundamental tone levels measured by the traversing microphone superimposed on the propeller operating maps at $0^{\circ}$ and $10^{\circ}$ propeller axis angle of attack. Figure 13(a), at $0^{\circ}$ angle of attack, is a repeat of figure 3 with superimposed 1 ines of constant tone SPL. Figure 13(b) presents corresponding results for $10^{\circ}$ angle of attack. Figure 13 combines the acoustic effects of increasing blade tip speed (decreasing advance ratio, $\mathrm{J}$, at constant blade angle) as was partially shown in figure 11 with the acoustic effects of changing blade angle ( $f 1 g .12)$. This results in an overall 
acoustic "picture" of the effect of the blade operating parameters on maximum fundamental tone levels.

Wing installation effects. - Three wing sets were installed downstream of the propeller to investigate the acoustic effects of propeller-wing interaction. Results are presented which show the acoustic effects of wing spacing, propeller droop, and inboard-up/inboard-down operation.

BPF tone directivity. - Figure 14 shows the effect of wing installation on the fundamental tone levels as measured by the translating microphone probe as would be measured by an observer below an aircraft. The wings were installed at their minimum spacings and the propeller was operated at takeoff design conditions. There was $0^{\circ}$ propeller droop, that is, the wing chord line was parallel with the propeller shaft axis. At $0^{\circ}$ angle of attack (fig. 14(a)) there is a small tone increase assoclated with the straight and swept-inboard down wing configurations near the propeller plane.

However, at $10^{\circ}$ angle of attack (fig. 14(b)) there is a definite tone level increase associated with the presence of wings. A $5 \mathrm{~dB}$ tone increase is shown for the straight wing, with nearly that much increase for the inboarddown swept wing. The inboard-up swept wing showed only a 2 dB tone increase near the propeller plane. The severity of the propeller interaction with the wing upwash is minimized with inboard-up operation, and this is supported by the acoustic results of figure 14(b). Reference 7 1ikewise noted there was increased drag assoclated with inboard-down wing installation.

Tone noise with harmonic order. - Figure 15 shows maximum tone noise levels as a function of harmonic order for the propeller alone and the straight wing at minimum spacing. The slope of decreasing tone level with harmonic order is similar for all measured tone orders and for the two configurations presented.

Wing spacing effect. - The effects of propeller-wing spacing is of concern due to structure and weight penalties associated with greater spacing. Figures 16 and 17 show the effect of wing spacing on maximum tone noise as measured by the translating microphone probe. The results of figure 16, for the straight wing, show no clear spacing effects on the maximum tone noise except possibly at $10^{\circ}$ angle of attack. However, the presence of the wing in all cases seems to increase the maximum tone level by about $2 \mathrm{~dB}$.

The BPF tone results for the inboard-up swept wing (fig. 17) show some decrease in tone level in going from the minimum to the larger spacing. The results for the first overtone, $2 \times B P F$, are less clear but the same trends seem to be present. However, the tone levels for the inboard-up swept wing appear to approach those for the propeller alone as wing spacing is increased. The propeller pitch change axis-wing leading edge spacing for the Gulfstream II flight tests will be 0.39 axial wing chords.

Effect of droop angle. - In an actual propeller-wing installation the propeller axis would normaliy be angled downward from the wing chord line. This downward tilt is referred to as "droop" angle in the results of figure 18. In this figure the maximum BPF and $2 \times B P F$ tone levels measured by the translating microphone probe (below an aircraft) are shown as a function of propeller 
angle of attack. The straight wing was installed at the minimum propeller-wing spacing. A line is drawn through the data for zero droop. The results in figure 18 show that the BPF tone level is controlled by the propeller angle of attack and by the presence of the straight wing, but is quite insensitive to the range of droop angles tested, or to small changes in the independent wing angle of attack.

The $2 \times B P F$ results do show some sensitivity to droop angle in the range of $0^{\circ}$ to $7^{\circ}$ of propeller angle of attack, with little effect at $10^{\circ}$ angle of attack. However, the $2 \times B P F$ tone is generally about $20 \mathrm{~dB}$ lower than the BPF tone and of littie consequence in the overall spectrum.

Wing pressures. - The two swept wings were fitted with flush-mounted pressure sensors as shown in figure 19. The middle sensor was located at the blade tip radius. The sensors were located on the propeller approach side of the wing in each installation, which was on the pressure surface for inboardup, and the suction surface for inboard-down.

Figure 20 shows the fundamental tone pressure levels measured by these sensors at three angles of attack. At $0^{\circ}$ angle of attack the pressure level is greatest at the blade tip location indicating wing interaction with the blade tip vortex. However, with increasing angle of attack the pressure distribution stays about the same for the inboard-down suction surface, but moves inboard for the inboard-up pressure surface, showing tip vortex migration.

\section{SUMMARY OF RESULTS}

A single rotation model turboprop. SR-7A was acoustically tested at simulated takeoff/approach conditions ( 0.2 Mach) in the NASA Lewis 9x15 anechoic wind tunnel. The propeller was tested with a wing in three tractor configurations (straight, $30^{\circ}$ swept, inboard up propeller rotation, and $30^{\circ}$ swept, inboard down propeller rotation). The propeller was operated at several tip speeds, blade setting angles, and angles of attack. The following significant results were observed in this study:

1. The maximum tone noise along a $1.68 \mathrm{~m}(5.5 \mathrm{ft})$ translating microphone survey (corresponding to an observer directly below an aircraft fiyover) increased in a regular manner with propeller angle of attack when the propeller axis rotated away from the translating probe (positive angle of attack). A $10 \mathrm{~dB}$ maximum tone increase was observed at $15^{\circ}$ angle of attack. A decrease of $5 \mathrm{~dB}$ was observed at the same location when the model was rotated to a $-10^{\circ}$ angle of attack toward the translating probe. Corresponding opposite effects were observed at the fixed microphones which were located on the tunnel wall on the opposite side of the model from the translating probe (i.e., increases at the probe were accompanied by decreases at the fixed microphones). Angle of attack induced blade loading is the cause of this noise asymetry.

2. The circumferential tone noise distribution with angle of attack shows an angular shift (i.e., rotation of pattern) from what would be produced if the noise generation instantaneously followed changes in circumferential blade loading (quasi-steady response). This shift is thought to be due phase shifts assoclated with the actual blade response to unsteady changes in blade loading. 
3. The sound pressure level spectra show considerable broadband noise content - espectally at higher blade tip speeds.

4. Downstream wings at 0.5 chord spacings (pitch change axis to wing leading edge) produce no tone increase at $0^{\circ}$ angle of attack. At $10^{\circ}$ angle of attack the straight wing only produces a $2 \mathrm{~dB}$ tone increase.

5. There were no large acoustic effects associated with changes in the independent wing angle (droop angle) with the straight wing at the minimum ( 0.54 wing chord) spacing at up to $10^{\circ}$ angle of attack.

\section{REFERENCES}

1. Mikkelson, D.C., Mitchell, G.A., and Bober, L.J., "Summary of Recent NASA Propeller Research," NASA TM-83733, 1984.

2. Metzger, F.B., "Progress and Trends in Propeller/Prop-Fan Noise Technology," AIAA Paper 80-0856, May 1980.

3. Dittmar, J.H., "Preliminary Measurement of the Notse From the $2 / 9$ Scale Model of the Large-Scale Advanced Propfan (LAP) Propeller, SR-7A," NASA TM-87116, 1985.

4. Parzych, D., Shenkman, A., Cohen, S., "Large-Scale Advanced Propfan (LAP) Performance, Acoustic and Weight Estimation," SP-06A83, Hamilton Standard, Windsow Locks, Ct, Jan. 1984. (NASA CR-174782)

5. Stefko, G.L., and Jeracki, R.J., "Wind Tunnel Results of Advanced High Speed Propellers in the Takeoff, Climb, and Landing Operating Regimes," AIAA Paper 85-1259, July 1985.

6. Metzger, F.B., and Rohrbach, C., "Benefits of Blade Sweep for Advanced Turboprops," AIAA Paper 85-1260, July 1985.

7. Welge, H.R., and Crowder, J.P., "Simulated Propeller Silpstream Effects on a Supercritical Wing," NASA CR-152138, 1978.

8. Knowles, K., "Broadband Noise - Its Prediction and Likely Importance for Advanced Propfans," AIAA Paper 86-1963, July 1986.

9. Dobrzynski, W.M., "The Effect on Radiated Noise of Non-Zero Propeller Rotational Plane Attitude," AIAA Paper 86-1926, July 1986.

10. Padula, S.L., and Block, P.J.W., "Predicted Changes in Advanced Turboprop Notse with Shaft Angle of Attack," Journal of Propulsion and Power, Vo1. 1, No. 5, Sept.-Oct. 1985, pp. 381-387.

11. Block, P.J.W., "Noise Radiation Patterns of Counter-Rotation and Unsteady Loaded Single-Rotation Propellers," Journal of Aircraft, Vol. 22, No. 9, Sept. 1985.

12. Dittmar, J.H., "Cruise Noise of Counter-Rotation Propeller at Angle of Attack Measured in Wind Tunne 1, "NASA TM-88869, 1986. 
13. Heldelberg, L.J., and Clark, B.J., "Preliminary Results of Unsteady Blade Surface Pressure Measurements for the SR-3 Propeller," AIAA Paper 86-1893, July 1986. 
TABLE I. - SR-7A PROPELLER DESIGN CHARACTERISTICS

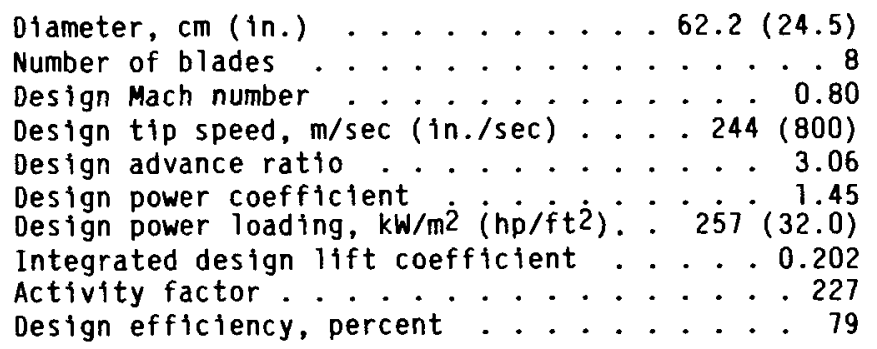


TABLE II. - SR-7A PROPELLER MODEL ACOUSTIC TESTS IN 9X15 ANECHOIC WIND TUNNEL

TEST CONFIGURATIONS

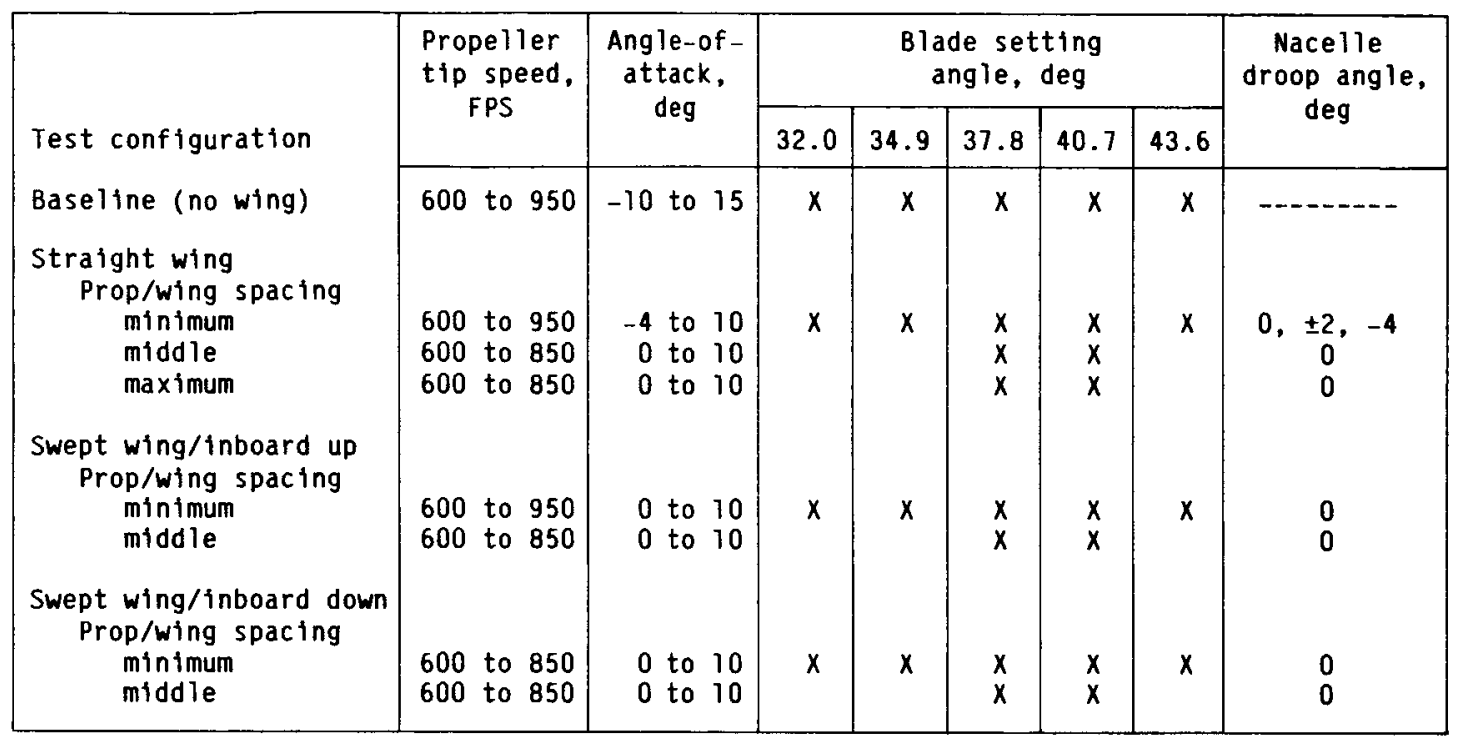

TABLE III. - SOUND LEVEL ADJUSTMENTS FOR

ANGLE OF ATTACK

[Adjusted to $1.68 \mathrm{~m}$ (66 in.) sideline.]

\begin{tabular}{|c|c|}
\hline $\begin{array}{c}\text { Angle of attack, } \\
\text { deg }\end{array}$ & $\begin{array}{c}\text { Adjustment, } \\
\mathrm{dB}\end{array}$ \\
\hline-10 & -1.5 \\
-5 & -0.7 \\
0 & 0 \\
5 & +0.7 \\
10 & +1.3 \\
15 & +1.9 \\
\hline
\end{tabular}




\section{GRIGINAL PAGE B OF POOR QUNUTY}

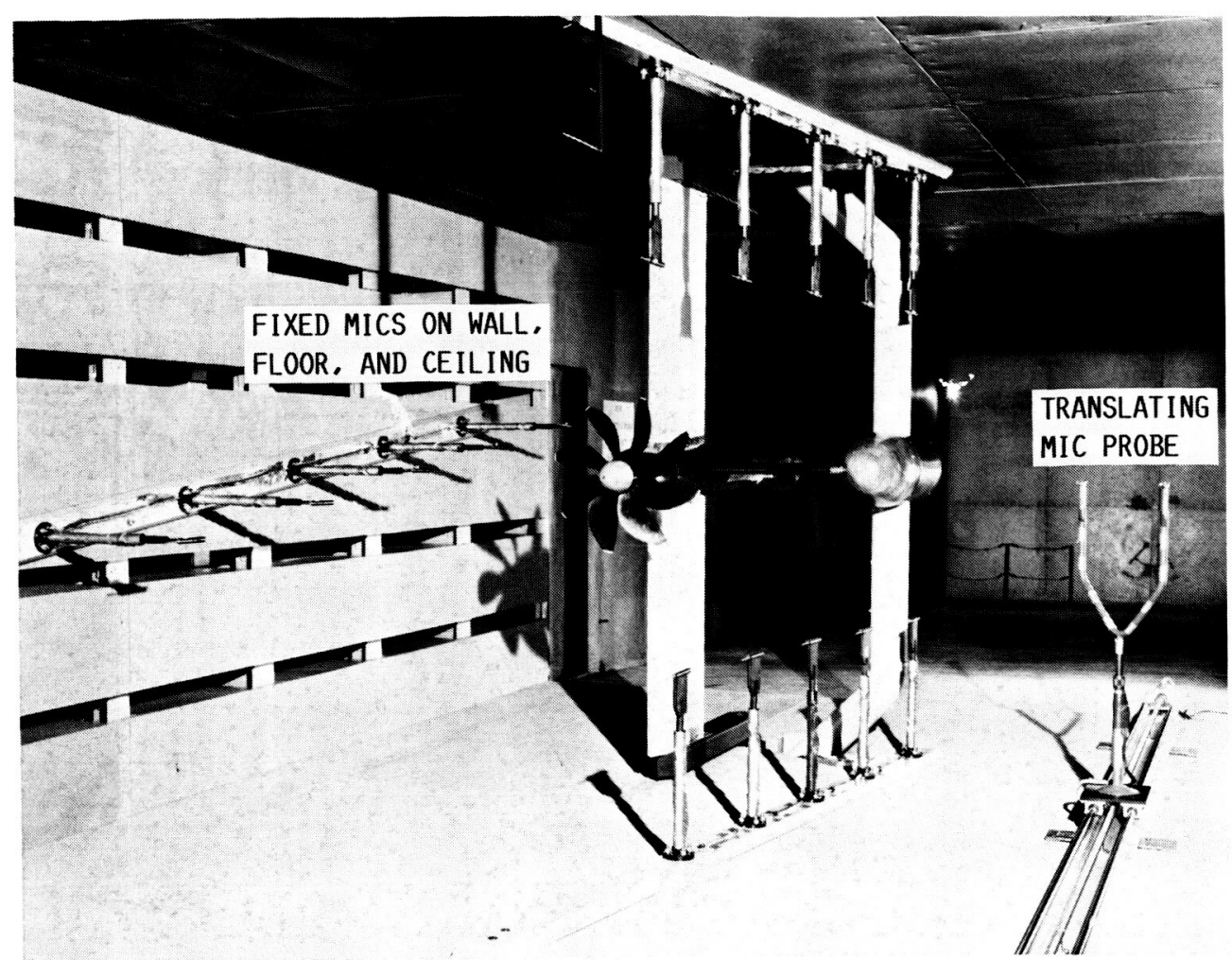

FIGURE 1. - PHOTO OF SR-7A TURBOPROP IN THE 9X15 ANECHOIC WIND TUNNEL SHOWING THE STRAIGHT WING INSTALLED.

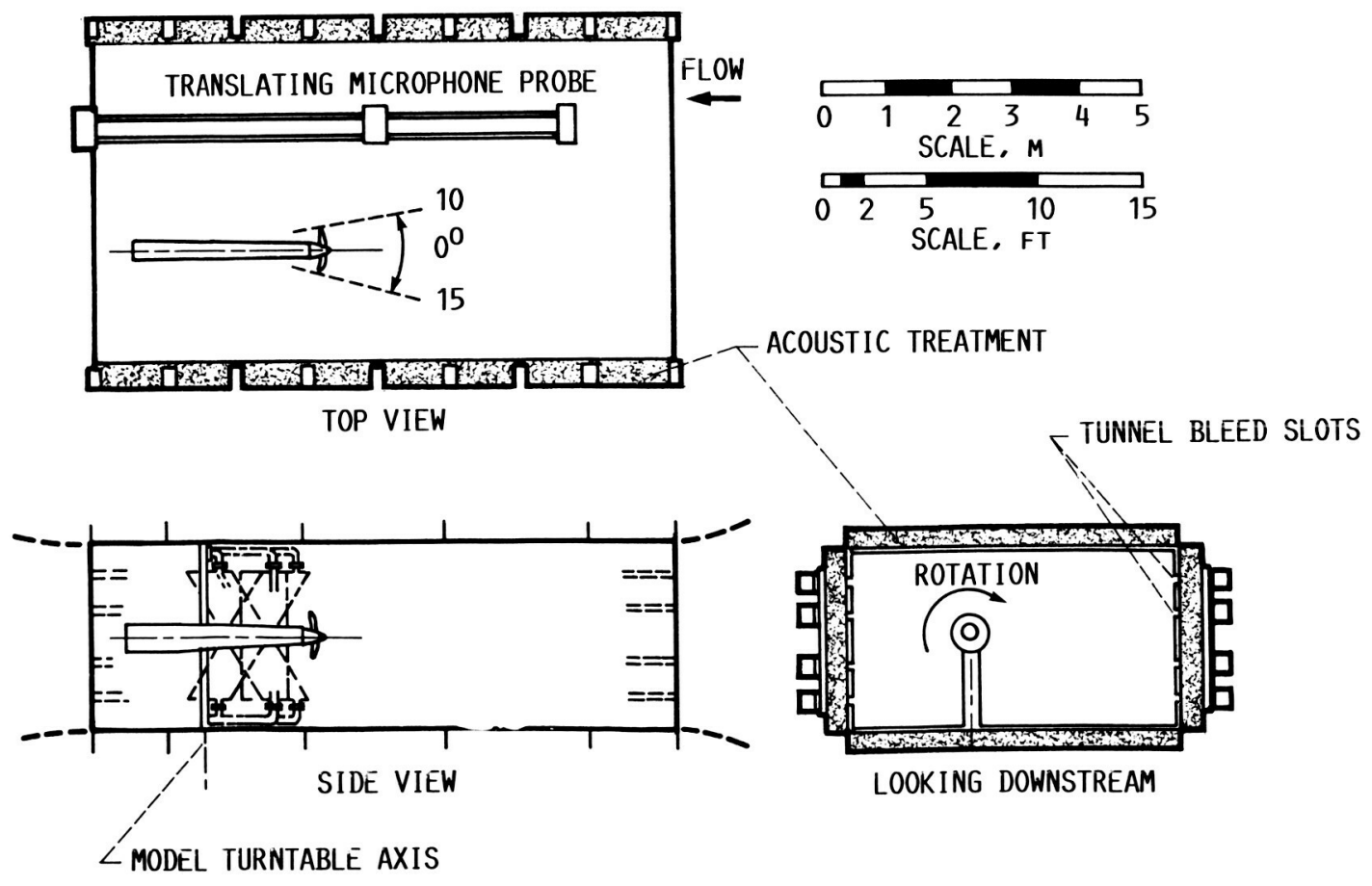

FIGURE 2. - PLAN VIEW OF THE 9X15 ANECHOIC WIND TUNNEL SHOWING THE SR-7A TURBOPROP INSTALLATION. 


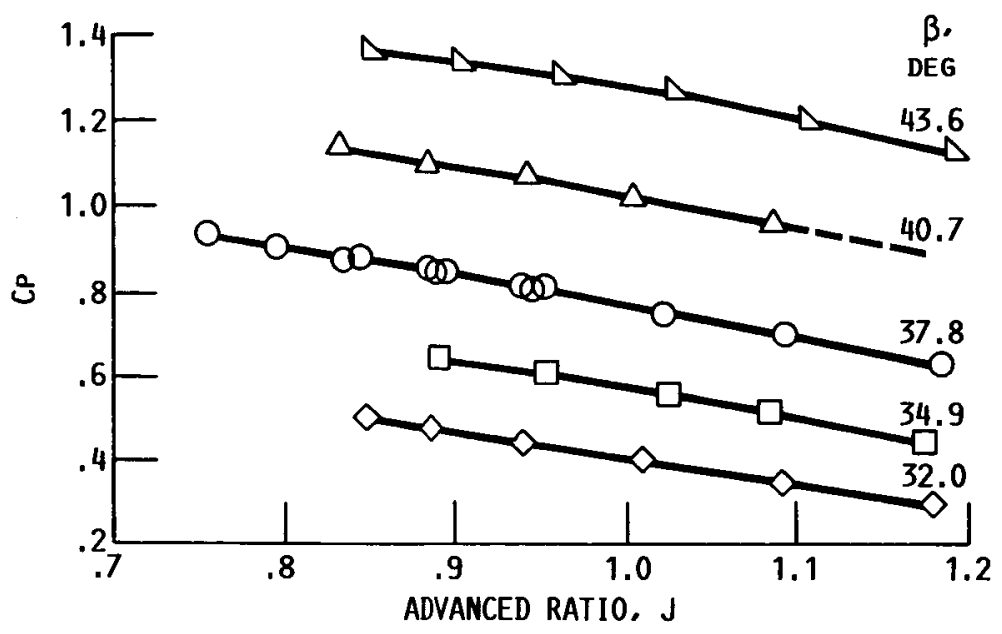

FIGURE 3. - PROPELLER OPERATING MAP FOR FIVE BLADE ANGLES TESTED AT $0^{\circ}$ ANGLE OF ATTACK, $M=0.2$.

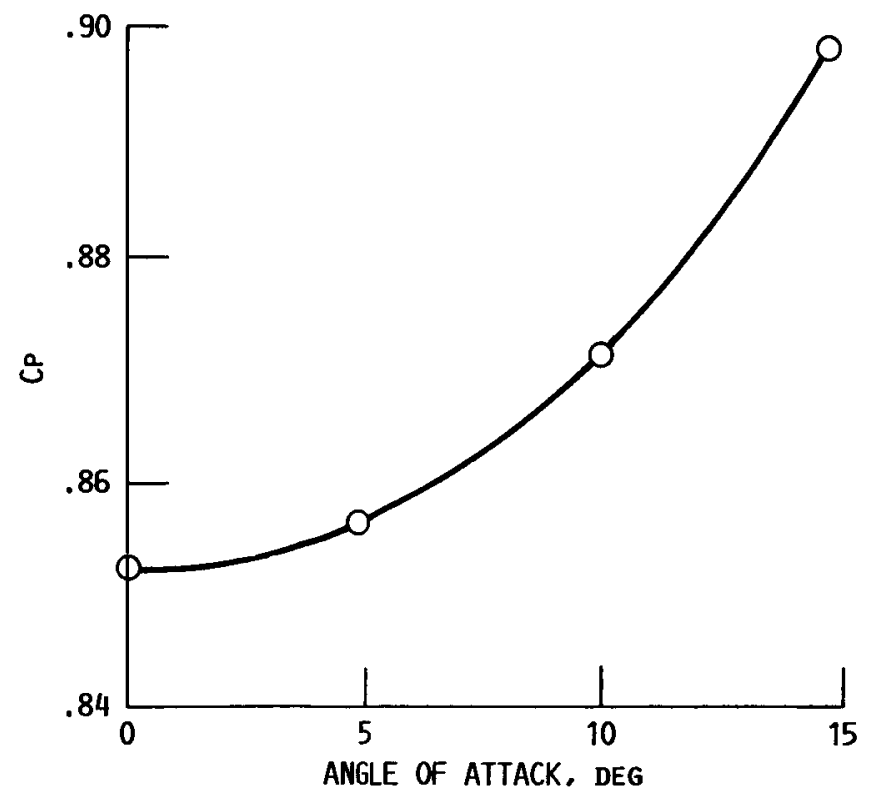

FIGURE 4. - EFFECT OF ANGLE OF ATTACK ON POWER COEFFICIENT ( $J$ REMAINS ESSENTIALLY CONSTANT) $U_{t}=244 \mathrm{M} / \mathrm{SEC}(800 \mathrm{FT} / \mathrm{SEC}), \beta=37.8^{\circ}$. 


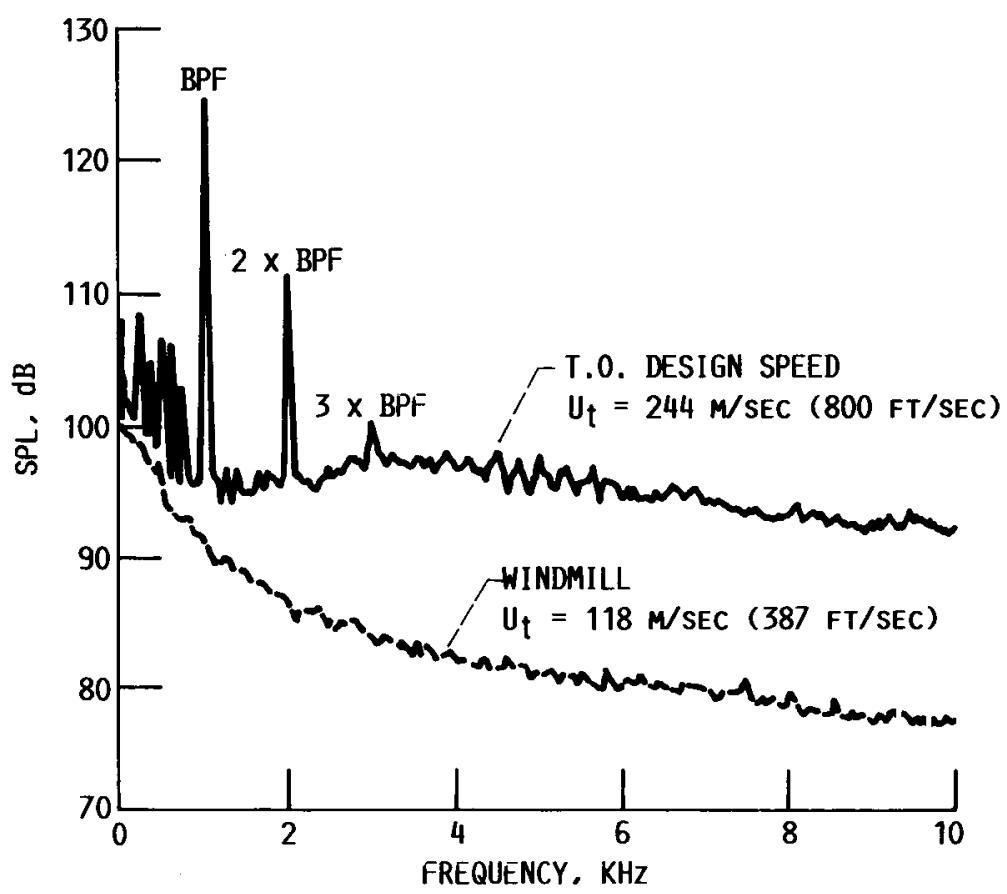

FIGURE 5. - SPL SPECTRA FOR $90^{\circ}$ FIXED FLOOR MICROPHONE $\alpha=0^{\circ}, \beta=37.8^{\circ}$. 

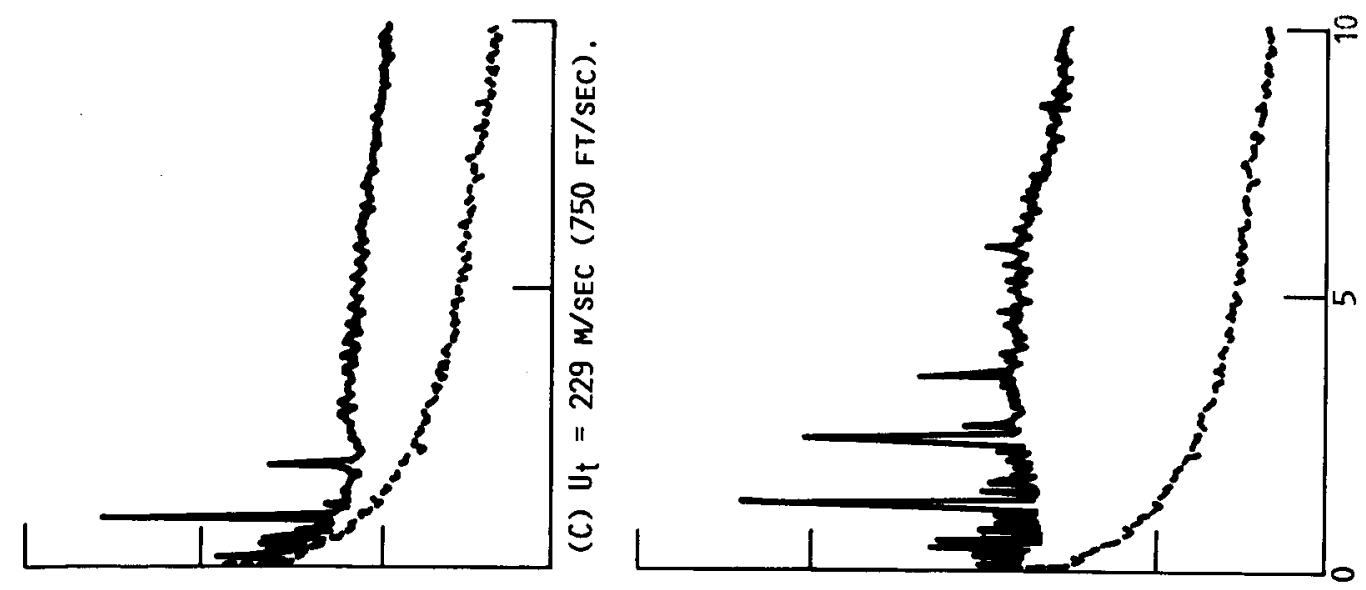

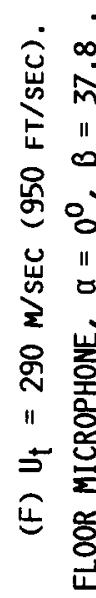
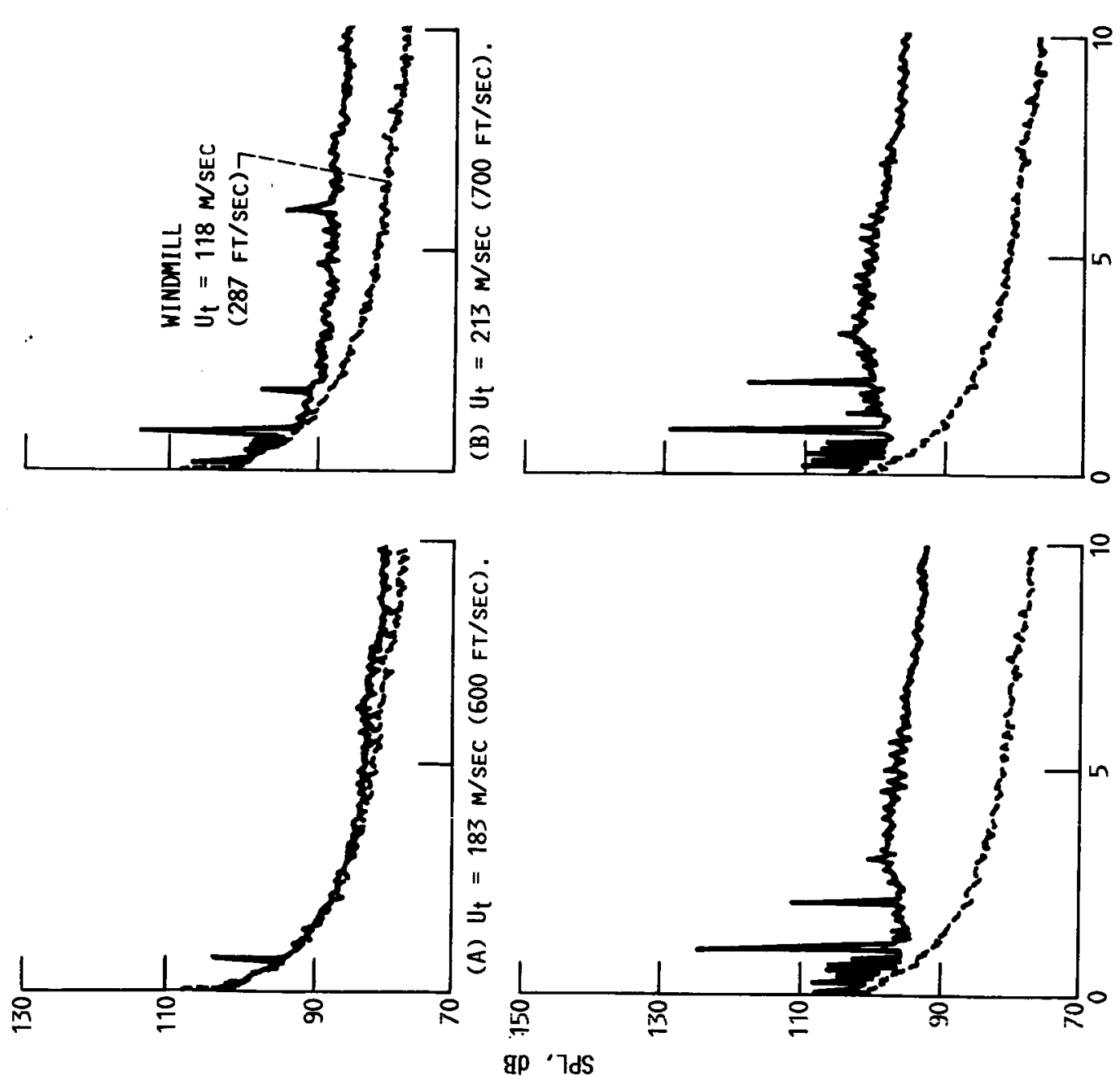

产

:

惫总

논

品吕

崫

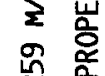

"

凹

운

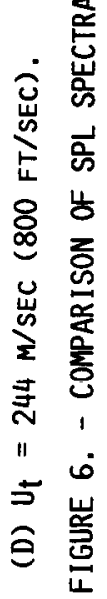
gp '7ds 


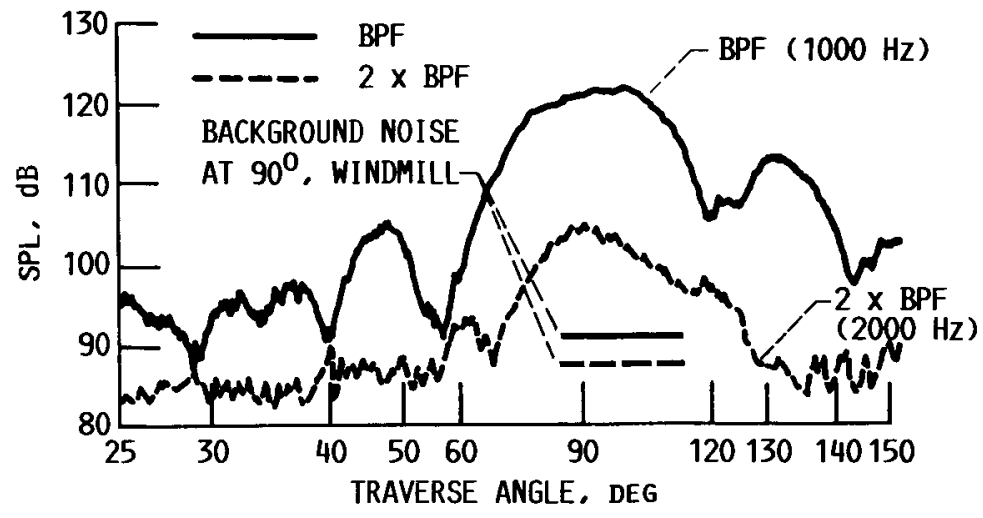

FIGURE 7. - SPL TONE DIRECTIVITY FOR NO WING CONFIGURATION $\alpha=0^{\circ}, U_{t}=244 \mathrm{~m} / \mathrm{SEC}(800 \mathrm{FT} / \mathrm{SEC})$, $\beta=37.8^{\circ}, M=0.2$.

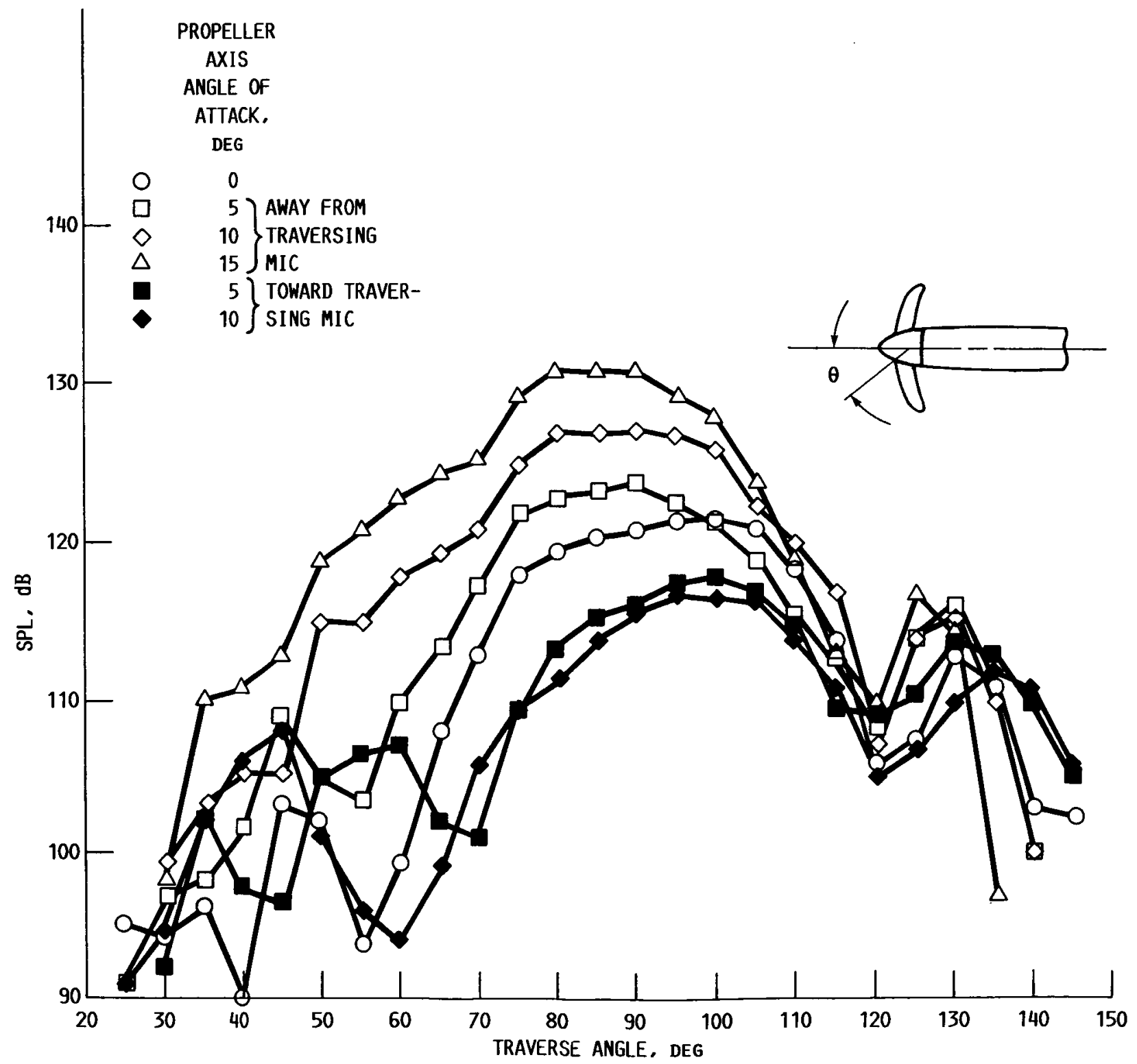

FIGURE 8. - EFFECT OF ANGLE OF ATTACK ON MAXIMUM BPF TONE NOISE NO WING CONFIGURATION, $U_{t}=244$ $M / \mathrm{SEC}(800 \mathrm{FT} / \mathrm{SEC}), \beta=37.8^{\circ}, M=0.2$. CORRECTED TO $1.68 \mathrm{M}(5.5 \mathrm{FT})$ SIDELINE DISTANCE. 


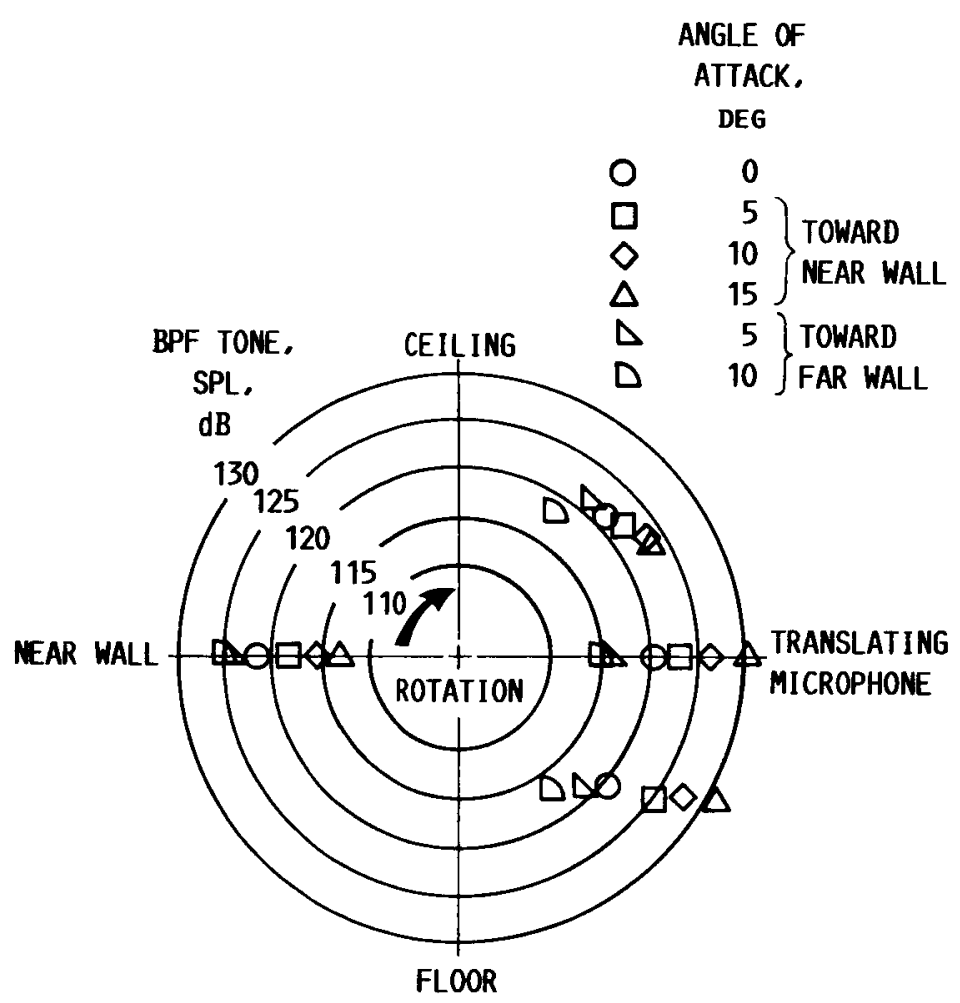

FIGURE 9. - EFFECT OF ANGLE OF ATTACK ON CIRCUMFERENTIAL BPF TONE NOISE (PROPELLER PLANE, VIEWING DOWNSTREAM, NO WING $) U_{t}=244 \mathrm{M} / \mathrm{SEC}(800 \mathrm{FT} / \mathrm{SEC}), \beta=37.8^{\circ}$, $M=0.2$. DATA CORRECTED TO $1.68 \mathrm{M}(5.5 \mathrm{FT})$ DISTANCE. 


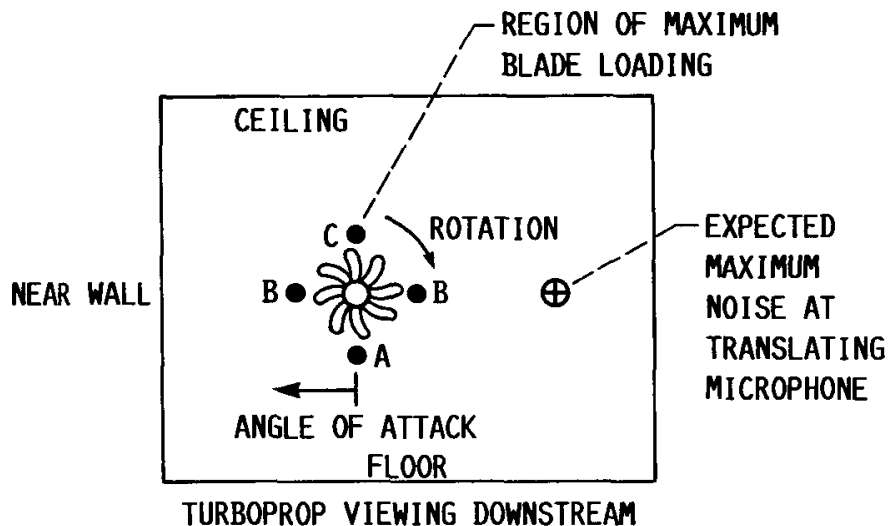

(A) PROPELLER INSTALLATION.

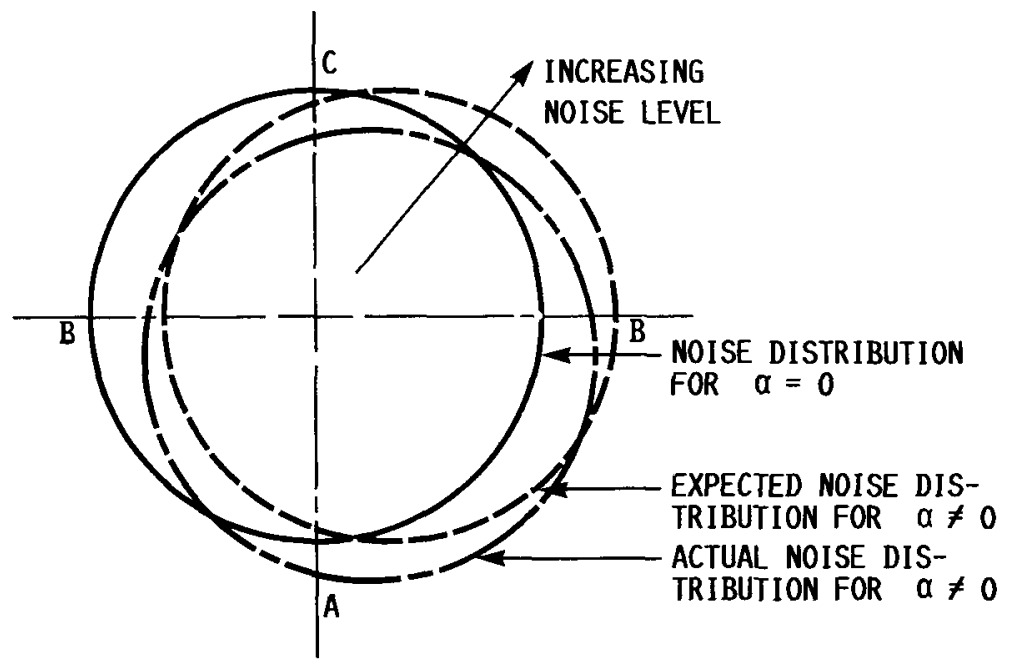

(B) PROPELLER NOISE FIELD.

FIGURE 10. - CIRCUMFERENTIAL DISTRIBUTION OF NOISE FIELD WITH ANGLE OF ATTACK. 


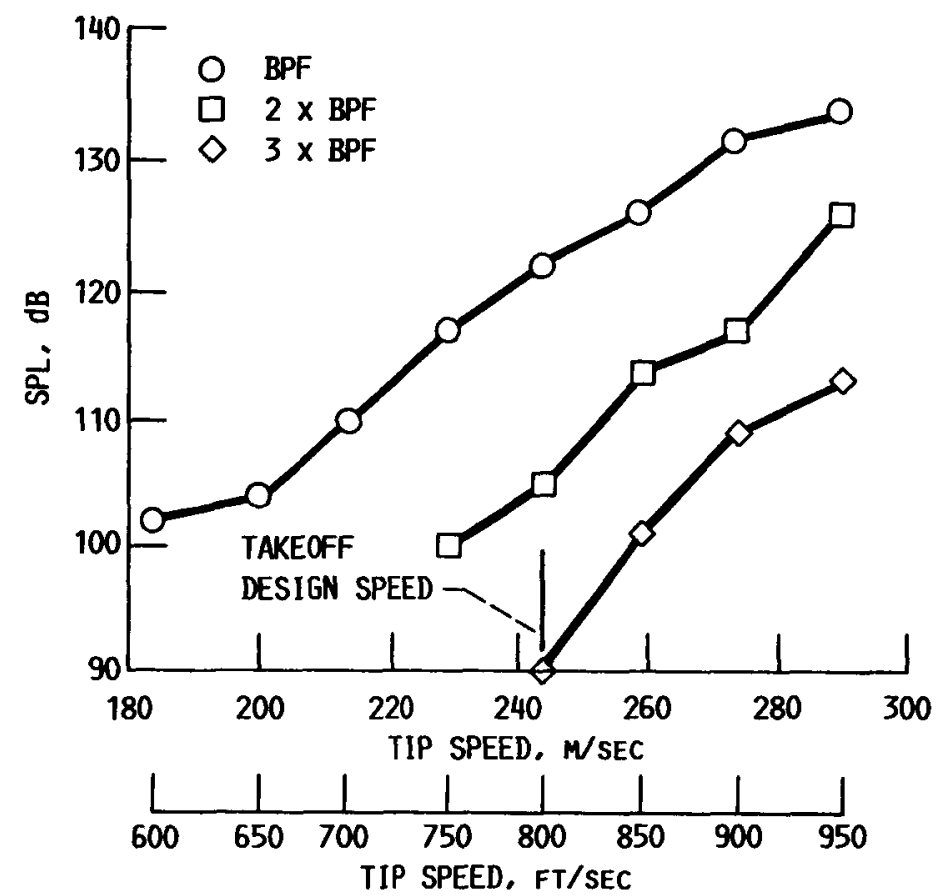

FIGURE 11. - MAXIMUM BPF TONE SPL AS A FUNCTION OF TIP SPEED, $\alpha=0^{\circ}, \beta=37.8^{\circ}, M=0.2$. 


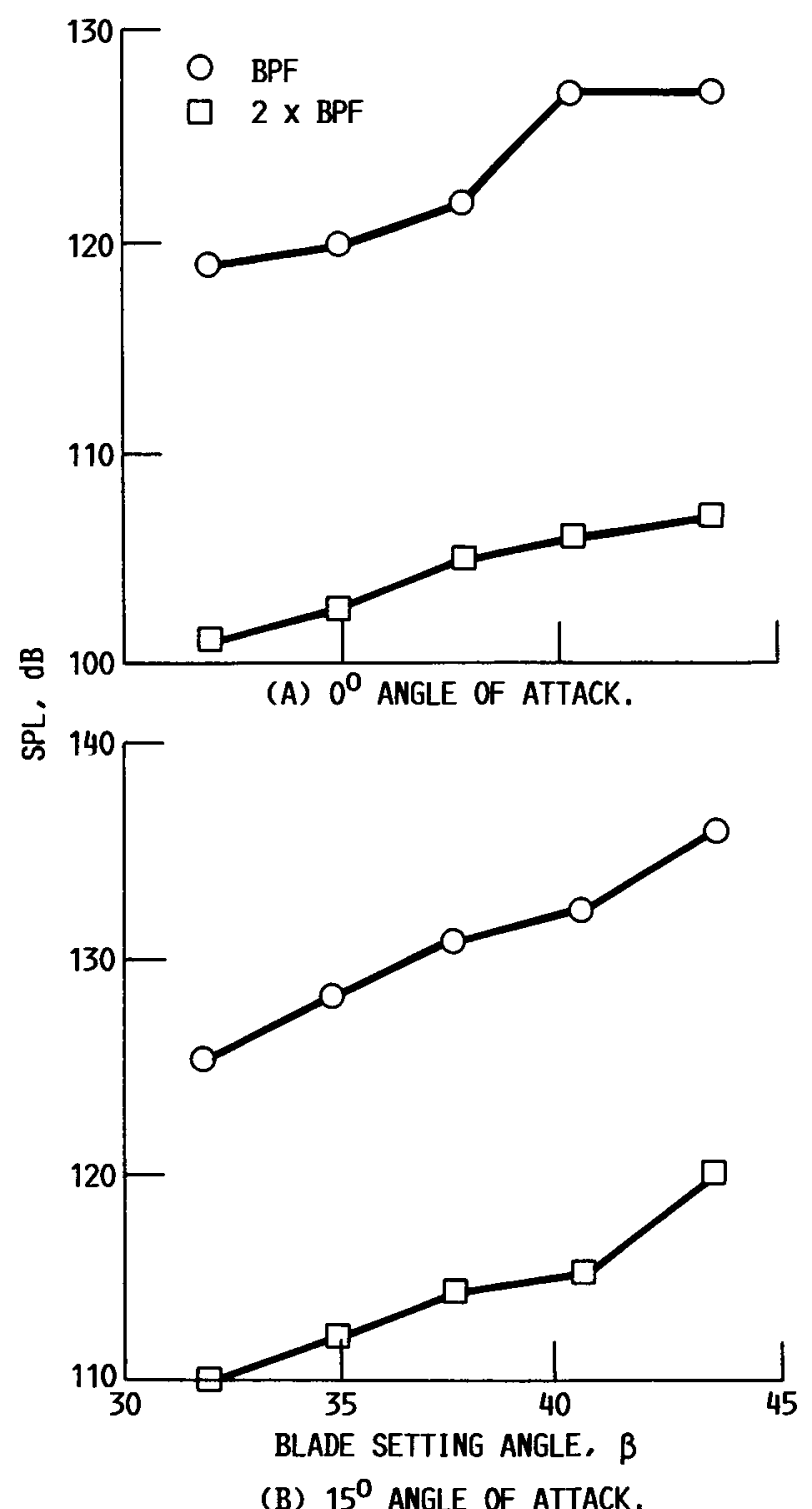

FIGURE 12. - EFFECT OF BLADE SETTING ANGLE ON MAXIMUM TONE NOISE $U_{t}=244 \mathrm{~m} / \mathrm{sEC}$ $(800 \mathrm{FT} / \mathrm{SEC}), \mathrm{J}=0.9, M=0.2$. 


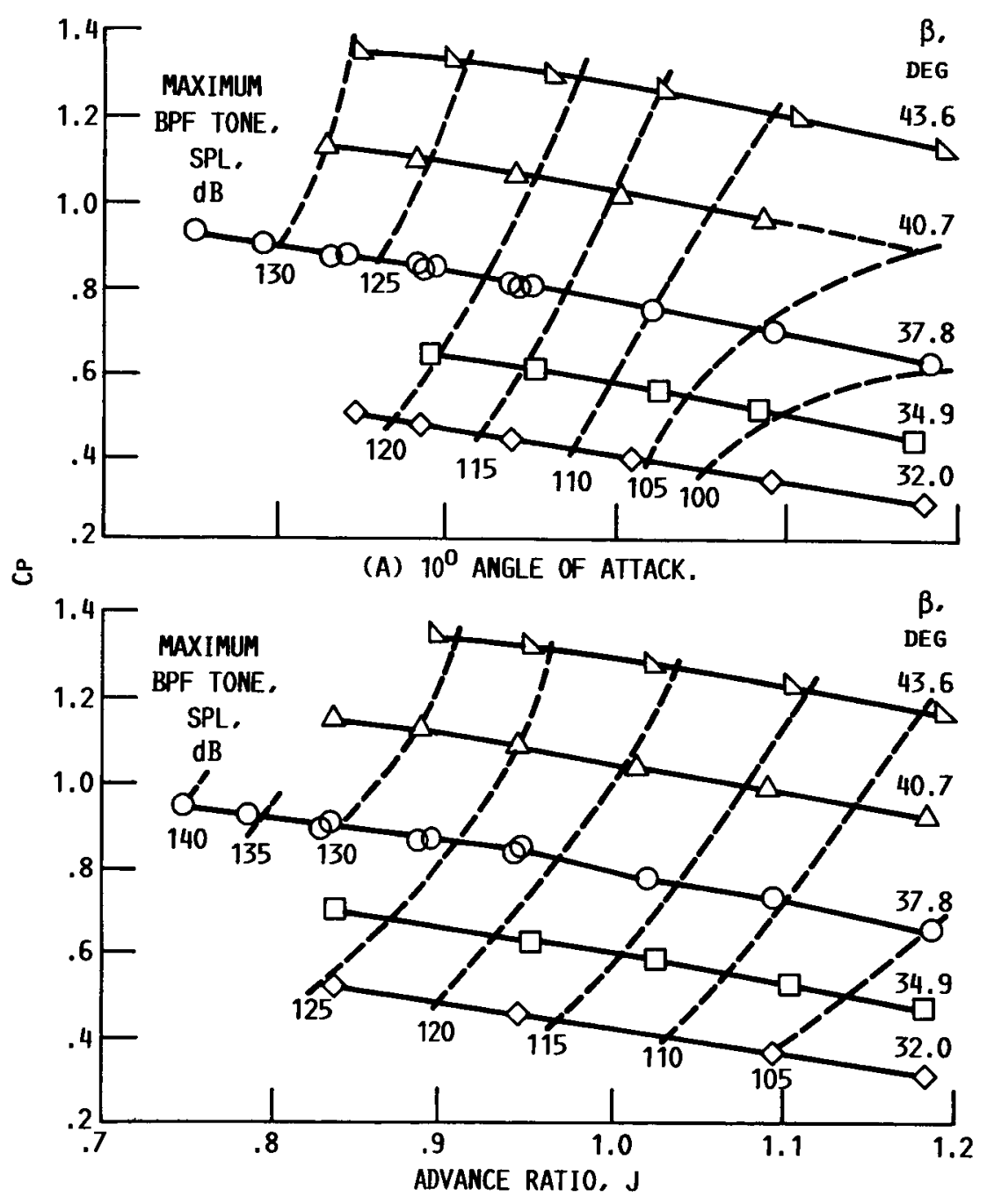

(B) $10^{\circ}$ ANGLE OF ATTACK.

FIGURE 13. - MAXIMUM BPF TONE LEVELS ON PROPELLER OPERATING MAP. 


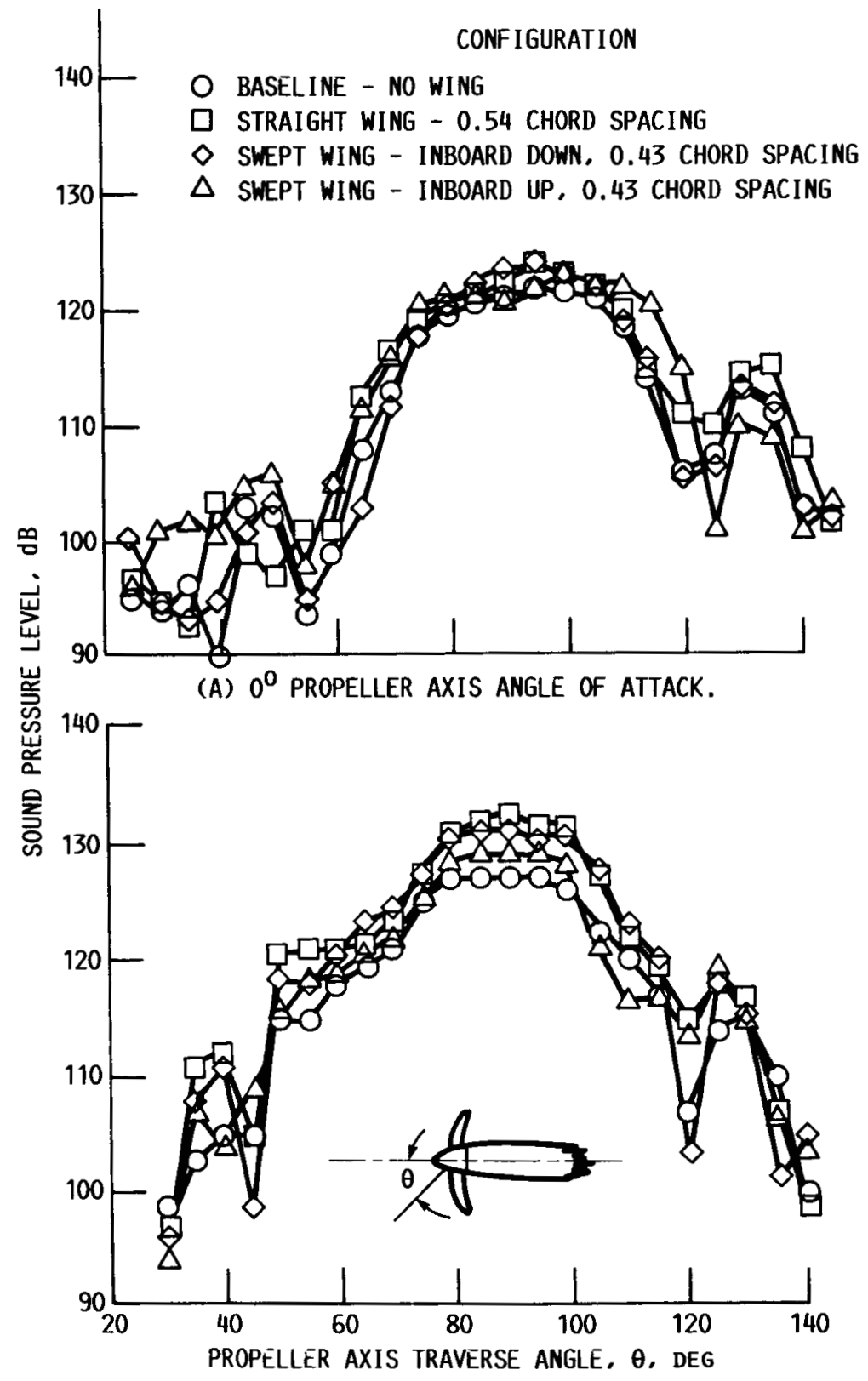

(B) $10^{\circ}$ PROPELLER AXIS ANGLE OF ATTACK.

FIGURE 14. - EFFECT OF WING CONFIGURATION ON BPF TONE FLYOVER DIRECTIVITY. $U_{t}=244 \mathrm{~m} / \mathrm{SEC}(800 \mathrm{FT} / \mathrm{SEC})$, $\beta=37.8^{\circ}, M=0.2$. DATA CORRECTED TO $1.68 \mathrm{M}$ (5.5 FT) SIDELINE. 


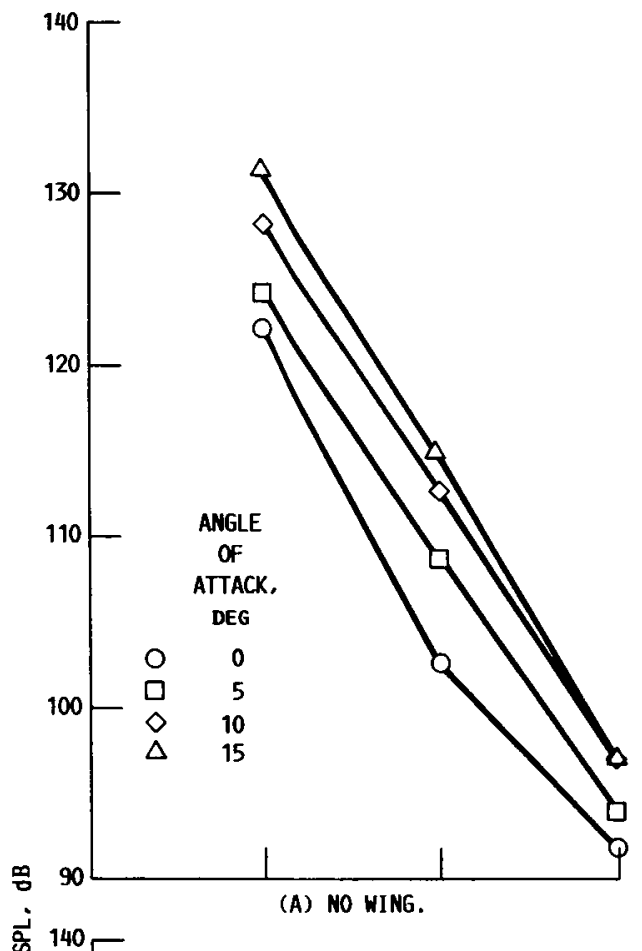

홍 140

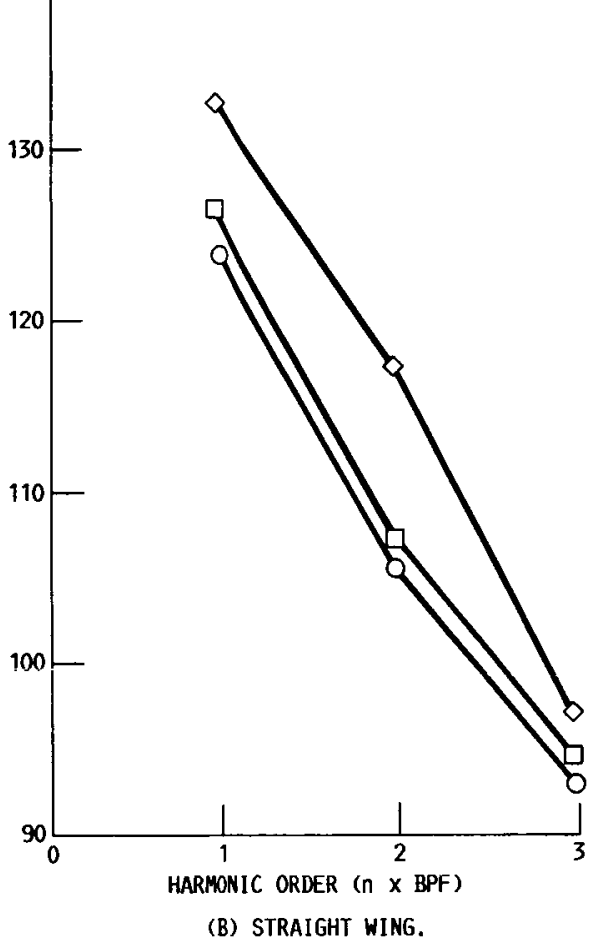

FIGURE 15. - MAXIMUM SPL AS A FUNCTION OF TONE NOISE, $U_{t}=244 \mathrm{~m} / \mathrm{SEC}(800 \mathrm{FT} / \mathrm{SEC})$, $\beta=37.8^{\circ}, \mu=0.2$. 


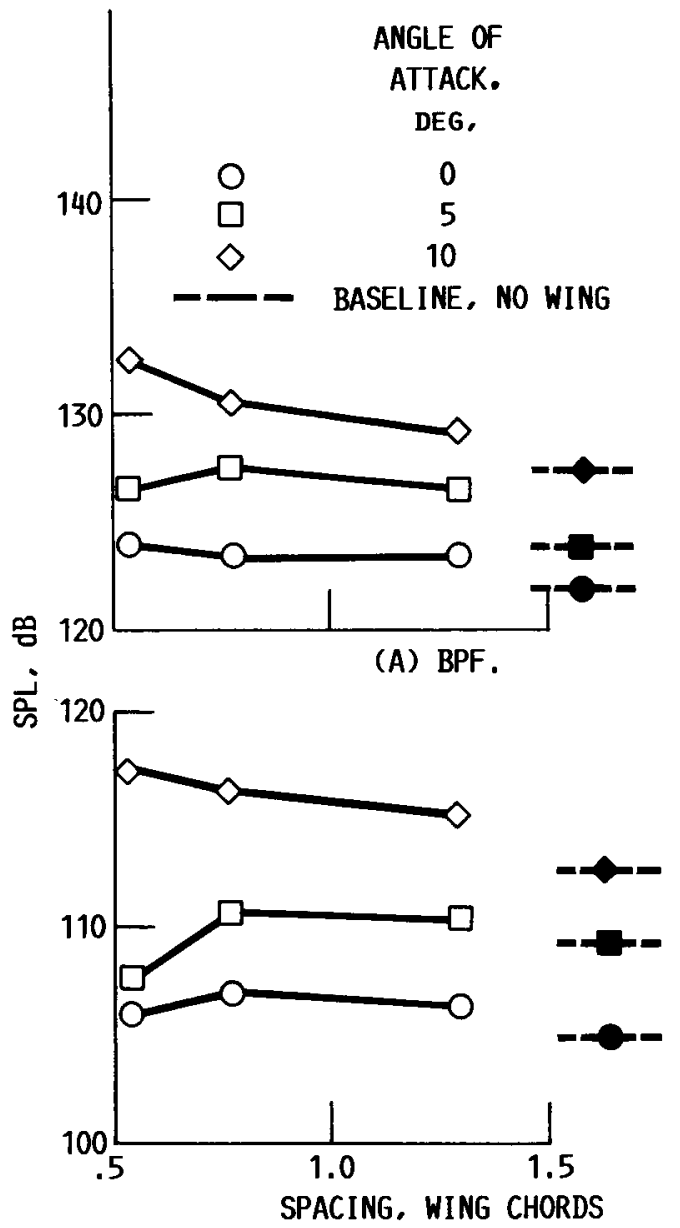

(B) $2 \times$ BPF.

FIGURE 16. - EFFECT OF STRAIGHT WING SPACING ON MAXIMUM TONE NOISE $U_{t}=244 \mathrm{~m} / \mathrm{sEC}$ $(800 \mathrm{FT} / \mathrm{SEC}), \beta=37.8^{0}, M=0.2$. 


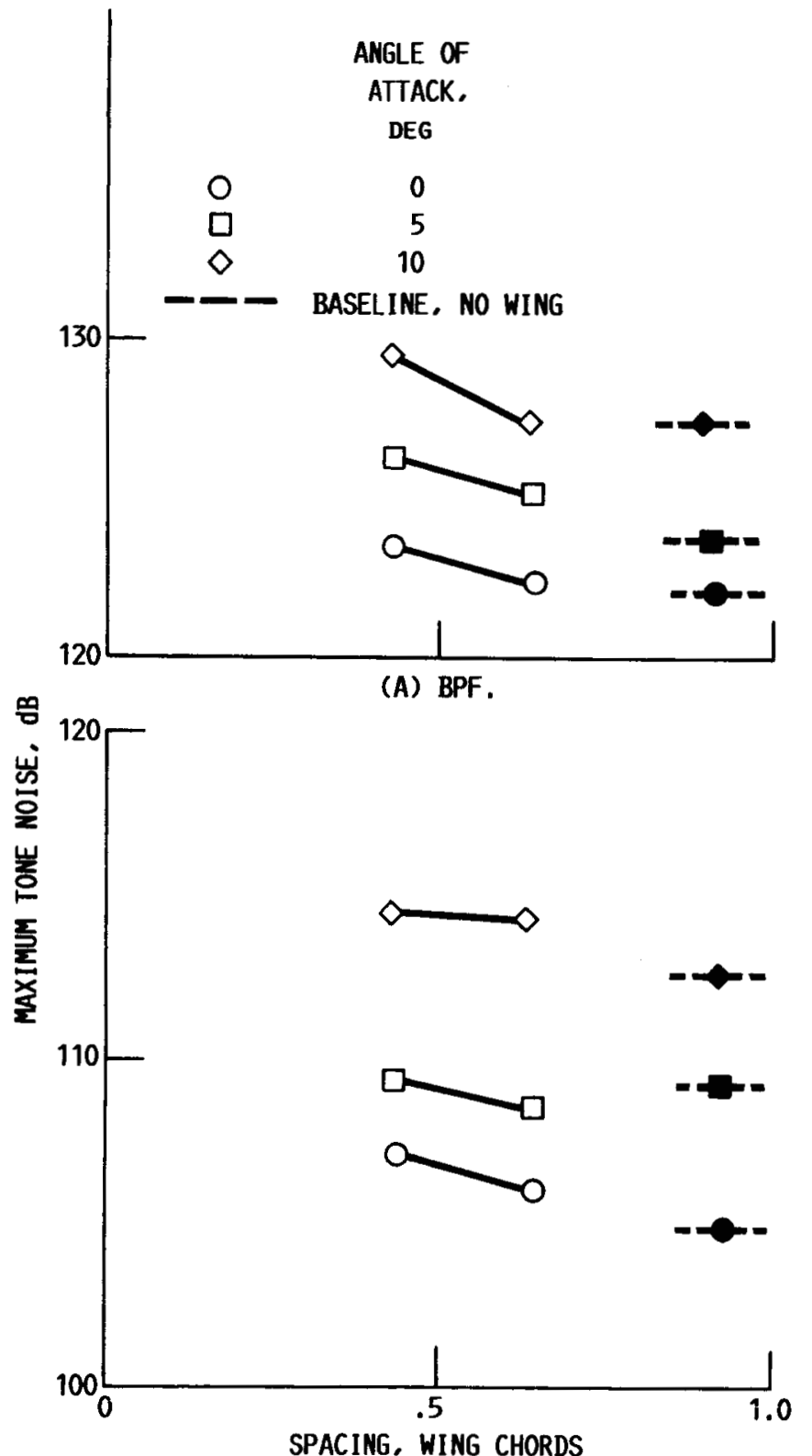

SPACING, WING CHORDS

(B) $2 \times$ BPF.

FIGURE 17. - EFFECT OF INBOARD UPSLEPT WING SPACING ON MAXIMUM TONE NOISE. $\quad U_{t}=244$ $M / \operatorname{SEC}(800 \mathrm{FT} / \mathrm{SEC}), \beta=37.8^{\circ}, M=0.2$. 

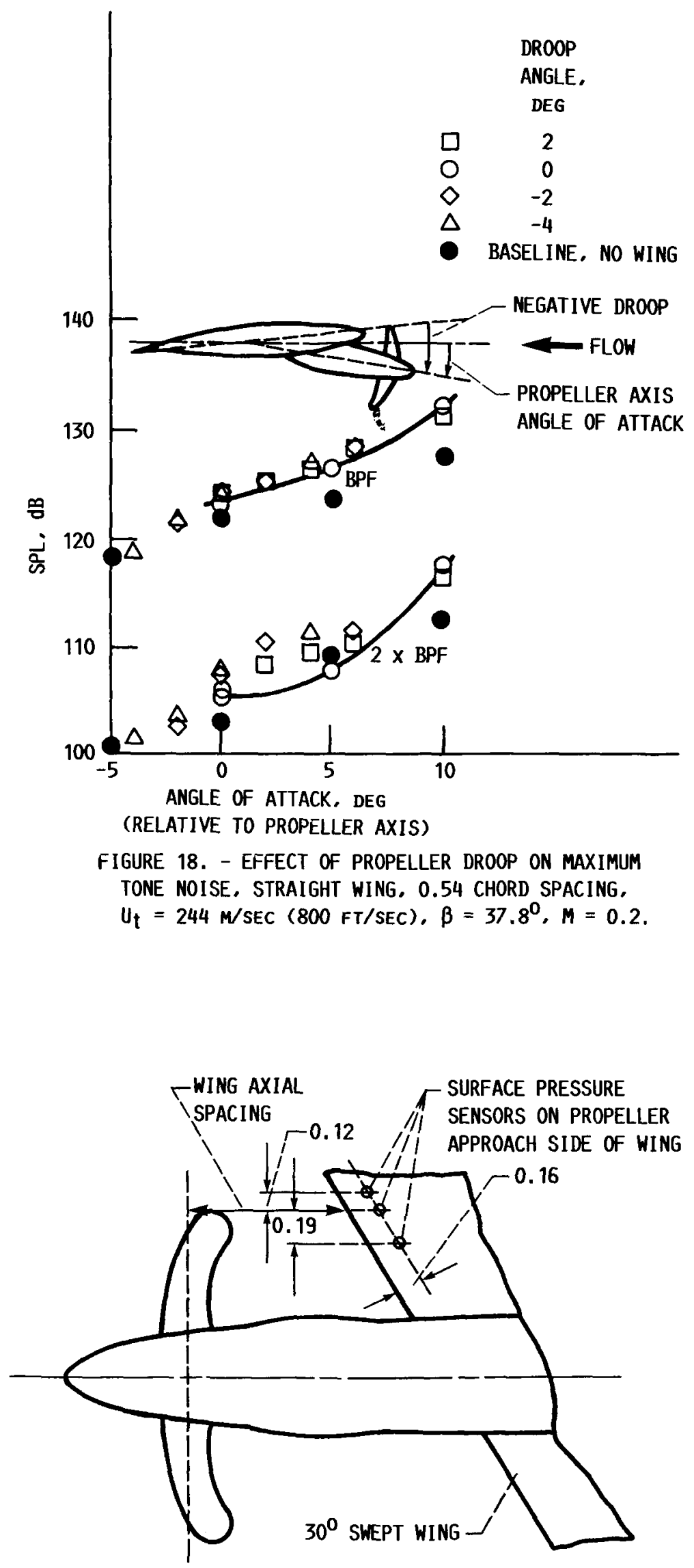

FIGURE 19. - INSTALLATION OF PRESSURE SENSORS ON SWEPT WING (DIMENSIONS IN PROPELLER RADII). 


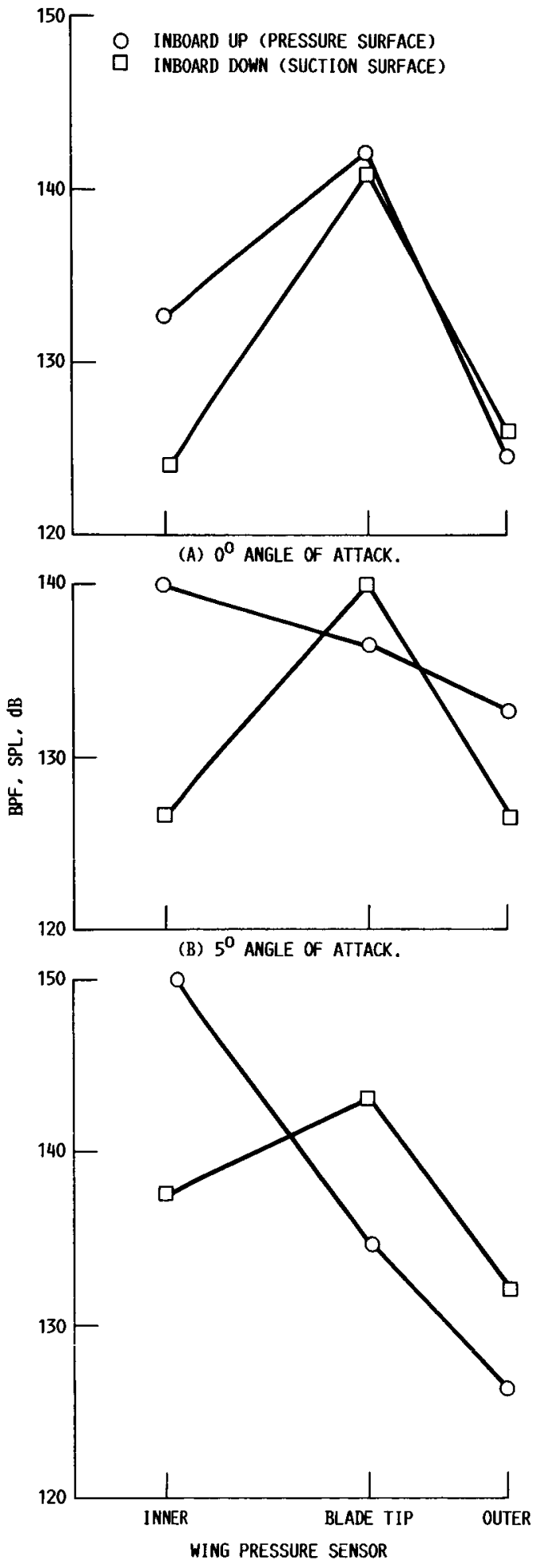

(C) $10^{\circ}$ ANGLE OF ATTACK.

FIGURE 20, - UNSTEADY PRESSURES ON SWEPT WING AT BPF, 0.43 CHORD SPACING, $U_{t}=244 \mathrm{~m} / \mathrm{SEC}$ $(800 \mathrm{FT} / \mathrm{SEC}), \beta=37.8^{\circ}, M=0.2$. 


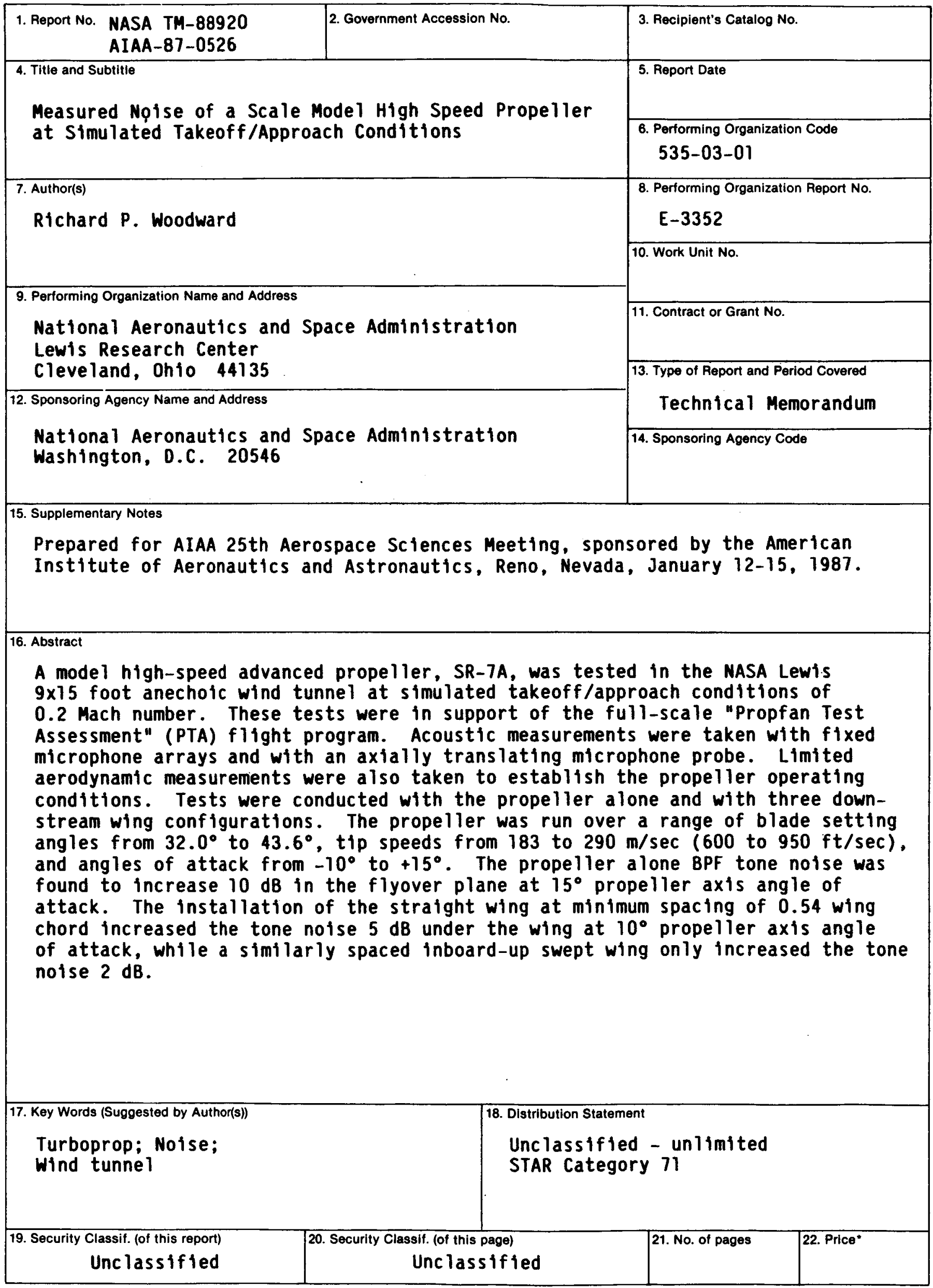

"For sale by the National Technical Information Service, Springfield, Virginia 22161 